\title{
Legados de megaeventos esportivos: considerações a partir de uma perspectiva crítica
}

CDD. 20.ed. 796.06

796.48

http://dx.doi.org/10.1590/1807-55092015000400675

\section{Resumo}

Um dos principais argumentos em prol da realização de megaeventos esportivos é que os mesmos geram desenvolvimento econômico, social, político e esportivo para as cidades/países sede. 0 objetivo deste trabalho é o de fazer alguns apontamentos sobre a noção de desenvolvimento em pauta, tomando como base autores que vêm discutindo a temática. Constatamos que o tipo de desenvolvimento facilitado por estes eventos tem beneficiado prioritariamente agentes bem posicionados com acesso privilegiado à instâncias de decisão, em detrimento de um tipo de desenvolvimento que favoreça a população como um todo. A promoção de desenvolvimento em prol do bem comum só é possivel na medida em que a decisão para se sediar, ou não, megaeventos esportivos, esteja alinhada com as metas de desenvolvimento de longo prazo das cidades e paises sede. Esta decisão deve também ser condizente com a realidade sociocultural e com a capacidade de se fornecer a infraestrutura e os recursos os necessários para se hospedar o evento. A realização de megaeventos esportivos não produz resultados positivos automaticamente. Para que isto ocorra, faz-se necessário um planejamento minucioso. Por exemplo, ao se pensar a construção e estruturas esportivas para o evento e como elas serão utilizadas depois do mesmo deve se considerar questões tais como: Quem será responsável pela manutenção destas estruturas e que recursos serão disponibilizados para isto? Quem utilizará estas estruturas? Que tipo de suporte o púbico alvo necessita para que possa otimizar esta utilização? Tanto o processo de planejamento de legados bem como a execução e avaliação de ações para a construção dos mesmos devem envolver a participação da população que será diretamente afetada com a realização dos eventos.

Palavras-chave: Esporte; Jogos Olímpicos; Jogos Paraolímpicos; Copa do Mundo; FIFA; COI.

\section{Introdução}

Um dos argumentos utilizado para a realização de megaeventos esportivos e investimento de recursos públicos nos mesmos, é que eles se constituem em um meio para a promoçáo do desenvolvimento econômico, social e político das naçôes e/ou cidades hospedeiras ${ }^{1-16}$. Ainda outro argumento, entre outros, é que estes eventos são oportunidades ímpares para o desenvolvimento do esporte nestas localidades ${ }^{7,17-22}$. A noção de desenvolvimento em pauta no contexto de megaeventos esportivos é, no entanto, problemática. Que desenvolvimento é este, e a quem, ou a que, ele se destina? Considerando estas questôes, o objetivo deste artigo éo de fazer alguns apontamentos, a partir de uma perspectiva crítica, sobre a noçáo de desenvolvimento defendida pelos proponentes destes eventos. Expandimos e atualizamos aqui algumas reflexóes que elaboramos em outro trabalho ${ }^{23}$, enfocando, desta vez, o que se sabe sobre "desenvolvimento esportivo". Visamos apresentar algumas ideias que possam contribuir para com o debate acadêmico relacionado com a temática, considerando que o Brasil sediou e estará sediando dois maiores eventos desta natureza: A Copa do Mundo de Futebol FIFA 2014 e os Jogos Olímpicos e Paralímpicos Rio 2016. 


\section{Que desenvolvimento é este? Desenvolvimento para quem?}

Vários autores têm questionado o pressuposto de que a realização de megaeventos esportivos beneficia a população e produz desenvolvimento sustentável $^{4,6,9,24-29}$. Whitson e Horne ${ }^{30}$, por exemplo, realizaram uma pesquisa sobre esta questão enfocando três casos específicos: Nagano (Japão) que sediou os Jogos Olímpicos e Paralímpicos 1998; a Coréia do Sul em parceria com o Japão que sediaram, em parceria, a Copa do Mundo de Futebol em 2002; e Montreal, que sediou os Jogos Olímpicos de 1976. Eles concluíram que nestes três casos, as propostas para se sediar os eventos foram feitas por elites políticas e corporaçóes que, embora tenham prometido grandes ganhos econômicos e sociais para os países, criaram infraestruturas para os eventos pouco sustentáveis e de retorno insatisfatório para a população como um todo. De acordo com os autores, os "grandes vencedores" dos megaeventos tendem a ser as construtoras e fornecedores de materiais de construção civil, canais de mídia, pessoas envolvidas em áreas diretamente relacionadas com a promoçáo dos jogos (empresas de "marketing", relaçóes públicas, propaganda), mercado imobiliário e agentes bem posicionados para se beneficiar com o aumento dos preços das propriedades.

Conforme argumentamos em outro trabalho ${ }^{23}$, vários fatores dificultam a promoção de legados positivos para a população em geral e para as cidades e países sede: Primeiro, instituiçóes organizadoras tais como o Comitê Olímpico Internacional (COI) e Federação Internacional de Futebol Associado (FIFA), impóem rígidas condiçóes para que os países hospedeiros possam realizar os eventos ${ }^{6,31}$. Eles exigem, por exemplo, infraestrutura de transporte público e a construção das instalaçôes esportivas dentro de determinados parâmetros, mesmo que estes não estejam alinhados com as necessidades e demandas da população local que potencialmente poderia também utilizar estas estruturas construídas. Ou seja, o bem comum normalmente não está dentre as preocupaçóes principais das comissóes organizadoras. O objetivo principal das mesmas é o de fazer com que o evento aconteça, otimizando ao máximo a sua participação no capital social, político e econômico gerado pelos eventos. Os governos e instituiçôes responsáveis pela organização destes eventos nas cidades e países hospedeiros acabam se tornando reféns desta lógica.

Segundo, os prazos para os preparativos para os megaeventos são relativamente curtos frente à infraestrutura que os mesmos demandam. Para agravar ainda mais a situação, o processo de planejamento tende a ser feito de cima para baixo, a favor de determinados interesses, com muito pouca - ou nenhuma - participação da população que será diretamente afetada ${ }^{8}$. Neste contexto, os países/cidade sede visam promover uma imagem de que "estâo prontos para o negócio" ao invés de buscar suprir as necessidades da população. Como resultado, a agenda de "desenvolvimento" tende a se centrar na construção de infraestrutura para a expansão e trâmite do capital. Metas de desenvolvimento tais como inclusão social e participação popular nas tomadas de decisóes, embora normalmente apareçam nos dossiês de candidatura, são rapidamente esquecidas no processo de planejamento e dotação orçamentária.

Terceiro, é extremamente difícil a aferição dos investimentos públicos realizados no contexto de megaeventos esportivos ${ }^{32-33}$. Detalhes da contabilidade normalmente ficam dispersos devido à participação de diversos órgãos públicos e privados, cada um com sua própria agenda e orçamento. Vários fatores dificultam a contabilização de gastos e lucros como, por exemplo, verbas para cobrir situaçóes de emergência e não previstas; contas não declaradas como despesas; verbas contratos sem licitação; e corrupção e propinas ${ }^{29,34-37}$.

Quarto, a dinâmica descrita acima, imposta pelos governos e entidades que promovem os eventos, corporaçóes vinculadas a estes eventos, e "experts" usualmente contratados para o planejamento dos mesmos, tende a reforçar uma lógica propícia para a reprodução de relaçóes hegemônicas de poder e para o agravamento de desigualdades sociais ${ }^{5,38-39}$.

Quinto, as instituiçôes organizadoras dos megaeventos esportivos e corporaçóes vinculadas a elas detêm total posse dos lucros produzidos com a sua marca, o que dificulta que agentes locais possam ter lucros com os eventos. Ou seja, a contrapartida financeira para os países hospedeiros tende a não ser substantiva frente aos investimentos feitos para que os eventos aconteçam.

Em decorrência das questốes levantadas acima, entre outras, as cidades/países hospedeiros normalmente náo conseguem cumprir suas promessas de desenvolvimento em prol do bem comum. No caso dos Jogos Olímpicos e Paralímpicos de Londres em 2012, por exemplo, o custo para a realização do evento ficou no mínimo cinco vezes maior do que o previsto. Havia uma previsão de gastos entre $£ \$ 1.7$ bilhóes e $£ \$ 2.1$ bilhôes (aproximadamente $\mathrm{R} \$ 5,3$ bilhóes e R $\$ 6,5$ bilhóes $)^{40}$. De acordo com o Comitê 
Organizador, os gastos foram de $£ \$ 9.3$ bilhóes (aproximadamente $\mathrm{R} \$ 36$ bilhóes), sem incluir dividas que foram deletadas das despesas oficiais dos Jogos e/ou que foram remanejadas para outras agencias ou contas do governo. Considerando estes gastos, o governo não conseguiu cumprir grande parte de suas promessas de legado para a população em geral.

Outro exemplo de dificuldade de se cumprir promessas pode ser verificado no caso dos Jogos Pan-Americanos e Parapan-americanos Rio 2007. Quando o Rio de Janeiro se candidatou como cidade sede, o governo brasileiro previa um gasto de R\$ 410 milhóes. No entanto, segundo a avaliação final de custos, o país gastou $\mathrm{R}$ \$ 3,7 bilhóes no evento, o que significou um acréscimo de $793 \%$ no orçamento ${ }^{41}$. O governo justificou este aumento com o argumento de que aproveitaria a oportunidade para construir instalaçóes esportivas melhor elaboradas para fomentar o desenvolvimento do esporte no país e atender os requerimentos do COI para uma futura candidatura do país à sede dos Jogos Olímpicos e Paralímpicos em 2016. No entanto, apesar de todo este investimento, o acesso aos equipamentos construídos ficou em grande parte restrito à população. Além disto, como algumas instalaçóes não preencheram os requisitos do COI, estão sendo reformadas ou reconstruídas para os Jogos Rio $2016^{42}$.

Experiências anteriores revelam que o legado da realização de megaeventos esportivos tende a ser negativo para grande parte da população que financia boa parte destes eventos através de impostos. Estes também tendem a contribuir para com o agravamento de problemas sociais em função das obras necessárias para preparaçáo para o evento. $\mathrm{Ou}$

\section{Desenvolvimento esportivo?}

São poucos os estudos confiáveis que investigaram se a realização de megaeventos esportivos fomenta o desenvolvimento do esporte, e mais especificamente, os níveis de atividade física (AF) da população em países/cidades sede $7,14,17,22,44-45$. A confiabilidade de estudos desta natureza tem sido questionada, uma vez que os mesmos são muitas vezes encomendados pelos próprios organizadores dos eventos e/ou outras entidades interessadas. Estes estudos têm também sido questionados porque muitas variáveis interferem com o engajamento da população em atividades físicas e esportivas, o que impede que se estabeleçam relaçôes de causa e efeito entre tais eventos e os níveis seja, eles promovem uma concentração de recursos públicos em áreas estratégicas para a realização do evento em detrimento de investimentos em outras áreas fundamentais para a promoção do desenvolvimento humano, tais como saúde e educação. Eles também tendem a promover desigualdade social: incentivam o desenvolvimento de determinadas regiôes das cidades sede em prejuízo de outras que talvez tivessem mais necessidade, a exemplo do que aconteceu no Rio de Janeiro no caso dos Jogos Pan-americanos e Parapan-americanos em $2007^{43}$. Vimos também isto acontecendo em várias cidades sede no processo de preparaçáo para a Copa do Mundo de Futebol da FIFA. No caso de Curitiba, por exemplo, a realizaçáo de apenas quatro jogos da Copa de 2014 promoveu a revitalizaçáo de uma das melhoras vias de Curitiba - a Av. das Torres - e outras vias importantes que levam até a Arena do Atlético, onde os jogos ocorreram. Estas vias já estavam entre as melhores da cidade antes das reformas. No entanto, receberam recursos para sua melhoria. Enquanto isto, algumas áreas da capital continuam com esgoto a céu aberto e vias de acesso que não apresentam condiçôes mínimas de tráfego.

Acreditamos que a realização de megaeventos esportivos promove "desenvolvimento" sim, mas desenvolvimento dentro de uma determinada perspectiva e centrado em alguns setores da sociedade. Este desenvolvimento é intencionalmente planejado e definido por agentes e instituiçóes bem posicionados que buscam benefícios para si próprios e para seus aliados ${ }^{23}$. A população, de uma forma geral, tende a náo ser diretamente favorecida por este tipo de desenvolvimento no longo prazo.

de AF dos indivíduos ${ }^{12,14,45-47}$. Ainda outro complicador relacionado com este tipo de investigação é que os protocolos que levantam os níveis de $\mathrm{AF}$ da população tendem a ser modificados com o tempo, dificultando comparaçóes entre o que acontece antes e após o evento ${ }^{45,48}$. Tomando como base os poucos estudos disponíveis sobre a temática, faremos abaixo um compilado de suas principais conclusóes.

Um dos aspectos positivos dos megaeventos esportivos é que eles podem levar os países/cidades sede a criar espaços e equipamentos, que por sua vez, podem propiciar o envolvimento da população, principalmente crianças e jovens, em $\mathrm{AF}^{49}$. 
Eles podem também promover um maior interesse pelo esporte ${ }^{50}$, conhecimento sobre o mesmo ${ }^{22}$, bem como a intençáo das pessoas de se engajarem em algum tipo de atividade física ${ }^{14}$. No entanto, embora os megaeventos esportivos possam inspirar os indivíduos a se envolverem mais em AF, os mesmos por si só não são suficientes para promover mudanças sustentáveis de comportamento neste sentido ${ }^{14,21,49-50}$. Quando este efeito ocorre, ele tende a se manifestar em pessoas já praticantes de AF e em casos onde outras iniciativas motivam a prática ${ }^{49}$.

Vale ressaltar, no entanto, que o "efeito inspiração" normalmente não dura no longo prazo, conforme pode ser observado, por exemplo, no caso dos Jogos Olímpicos e Paralímpicos de Atenas em 2004. Uma investigação desenvolvida por PAppous ${ }^{51}$ com base no Eurobarometer ${ }^{\mathrm{a}}$ os níveis de AF na Grécia aumentaram de 2003 para 2004 em 6\%. No entanto, em 2009, cinco anos após os Jogos, estes caíram para níveis inferiores à 2003. Também de acordo com alguns estudos, os megaeventos esportivos podem inclusive ter um efeito reverso nos níveis de AF da populaçáo, a exemplo do que aconteceu com a Austrália. Conforme o Australian Sports Commission $^{52}$ e BaUman et al. ${ }^{53}$, que estudaram os níveis de participação dos australianos antes, durante e depois dos Jogos de Sidney 2002, os níveis de AF dos mesmos diminuíram como consequência destes Jogos. A hipótese dos pesquisadores é a que talvez isto tenha ocorrido porque os australianos passaram de praticantes a telespectadores de esportes.

Ainda relacionado com o possível "efeito inspiração" de megaeventos esportivos, algumas pesquisas apontam que os atletas podem servir como "modelos esportivos" para ajudar as pessoas a se motivarem e se manterem motivadas para a prática ${ }^{21}$. Já outros apontam que a diferença percebida entre o que o atleta de alto rendimento consegue realizar, e o que o cidadão comum é capaz de fazer pode inibir a prática esportiva, uma vez que o último pode se sentir incapaz de alcançar os resultados de atletas que participam em competições de alto nível ${ }^{22,45,49}$.

Para que o "efeito inspiração" se consolide na prática, os países, cidades sede e organizaçôes esportivas necessitam de um planejamento de longo prazo que inclua incentivos à prática de atividade física, bem como a oferta de estruturas e programas esportivos $^{14,21,49-50}$. No entanto, isto tende a não ocorrer porque governos e organizaçóes esportivas normalmente nâo estão preparados para otimizar as oportunidades de promoçáo do esporte a partir da realização de megaeventos esportivos ${ }^{14,22,45}$.
No caso dos Jogos Olímpicos e Paralímpicos de Londres 2012, por exemplo, estabeleceu-se como meta que estes Jogos seriam um meio para "inspirar uma geração" para a prática de atividade física, e que, até 2012, dois milhóes de pessoas se tornariam mais ativas fisicamente ${ }^{19-20}$. O Reino Unido desenvolveu um planejamento de longo prazo e implementou açôes para atingir este objetivo. Dois estudos longitudinais e de larga escala estáo acompanhando os níveis de atividade física da população: O Active People Survey (APS), do Sport ENGLAND ${ }^{54}$, e uma pesquisa desenvolvida pelo Local Government Association (LGA) ${ }^{55}$. O primeiro estudo tem levantado dados sobre os níveis de AF da população via inquérito telefônico. Em sua última versão (APS8), incluiu 169.800 indivíduos com 14 anos ou mais de idade, comparando os dados levantados em abril de 2014 com dados levantados em 2005. De acordo com esta pesquisa, 1,7 milhóes a mais de pessoas se envolveram em atividades físicas e esportivas pelo menos uma vez por semana desde então. O APS ${ }^{8}$ também está investigando os níveis de atividade física regular de pessoas com deficiência. Uma das conclusóes deste estudo é que estes níveis aumentaram de 15,1\% em 2005 para 17,9\% em abril de 2014 .

O estudo do Local Government Association $(\mathrm{LGA})^{55}$ envolveu diferentes municípios da Inglaterra e País de Gales em 2013. Dos 110 municípios que responderam as questóes da pesquisa (29\% do universo total), três quartos afirmaram que houve um aumento de indivíduos acessando os seus equipamentos e atividades esportivas após os Jogos. Cabe ressaltar, no entanto, que o LGA trabalhou com dados limitados, uma vez que a taxa de retorno de resposta dos participantes foi baixa. Talvez os municípios que responderam à demanda da pesquisa sejam justamente os mais interessados na promoção do esporte, o que pode ter gerado um determinado viés nos resultados da pesquisa.

Com base nas pesquisas existentes, não temos como afirmar que existe de fato uma relação significativa entre a realização de megaeventos esportivos e o aumento dos níveis de atividade física da populaçãa ${ }^{21,49,56}$. Mesmo no caso do Reino Unido onde houve todo um planejamento neste sentido, os resultados não foram substanciais, conforme relatado acima. Cabe ressaltar também que, embora tenha existido uma grande expectativa de que os Jogos Paralímpicos poderiam deixar um grande legado para o desenvolvimento esporte Paralímpico na Grã Bretanha, alguns trabalhos sugerem que, embora atletas Paralímpicos tendam a ser individualmente valorizados, eles normalmente não são percebidos 
como modelos de inspiração, isto porque cada um dos atletas possuem limitaçóes que normalmente não se aplicam a todos; porque os mesmos tendem a não se descrever como pessoas com deficiência; e também porque normalmente não são vistos lidando com questôes cotidianas enfrentadas por pessoas comuns que possuem deficiências. Estes estudos também indicam que a realização dos Jogos Paralímpicos de Londres 2012 não eliminou atitudes negativas em relação às pessoas com deficiência, não aumentaram o financiamento para desporto Paralímpico, não melhoraram o transporte e a acessibilidade a diferentes locais, e não proporcionaram o desenvolvimento de profissionais mais preparados para trabalhar com o esporte adaptado. Ou seja, eles não geraram mudanças estruturais que pudessem facilitar novas formas de esporte e participação de atividade física por parte de pessoas com deficiência ${ }^{57-58}$.

Se por um lado não existem evidências suficientes que demonstrem que exista uma correlação entre a realização de megaeventos esportivos e desenvolvimento esportivo no sentido de maior envolvimento das pessoas com atividades físicas e esportivas, os países hospedeiros tendem a investir no desenvolvimento do esporte de alto rendimento. Estes investimentos, no entanto, tendem se centrar em determinadas modalidades em detrimento de outras, dependendo do potencial das mesmas de ganhar medalhas. Este foi o caso, por exemplo, do Reino Unido que náo só investiu massivamente no esporte de rendimento durante a preparaçáo dos Jogos Londres 2012, o que lhe rendeu mais medalhas do que em anos anteriores, mas também, logo após estes Jogos, aumentou em 11\% seus investimentos nesta direção visando preparar atletas de ponta para os Jogos Rio 2016. No entanto, ao mesmo tempo em que tem investido grandes quantias em modalidades que ganharam medalhas em 2012, como no caso do remo, vela e equitação (modalidades de difícil acesso à população), praticamente cortou recursos destinados à modalidades esportivas que não se saíram bem, como por exemplo, o handebol e o basquete ${ }^{59}$. Esta estratégia de se investir em modalidades que podem "render" medalhas pode ter um impacto negativo no desenvolvimento de modalidades que poderiam estar inspirando e, ao mesmo tempo, possibilitando um maior engajamento por parte da população nas mesmas. Vale ressaltar que o exemplo de atletas de alto rendimento e medalhas olímpicas podem inspirar os indivíduos a se envolverem em AF. No entanto, inspiração por si só não é suficiente para que eles se envolvam e continuem envolvidos neste tipo de atividade no longo prazo. Para que se possa atingir esta meta, os mesmos precisam de condiçóes para a prática (ex. acesso à estruturas esportivas e equipamentos, orientação por parte de profissionais do esporte, transporte para os locais da prática, etc.).

Com a vinda dos Jogos Pan e Parapan-americanos Rio 2007 e dos Jogos Olímpicos e Paralímpicos Rio 2016, o Brasil tem vivenciado um crescente interesse no esporte de rendimento. Conforme apontam alguns estudiosos, quando o ex-presidente Luiz Inácio Lula da Silva assumiu a presidência da República o governo Federal tinha como meta a democratizaçáo do acesso ao esporte para a população em geral. Esta agenda, no entanto, foi modificada em prol da preparação do país para uma série de megaeventos no país, como os Jogos Pan e Parapan-americanos, a Copa das Confederaçóes, a Copa do Mundo de Futebol da FIFA e os Jogos Rio $2016^{60-61}$. Isto pode ser comprovado quando se afere os investimentos no esporte brasileiro nos anos próximos aos Jogos Rio 2007.

Suélen Barboza Eiras de Castro, como parte de seu doutorado ainda em andamento no Departamento de Educação Física da Universidade Federal do Paraná, compilou e sistematizou dados do Portal Siga Brasil ${ }^{\mathrm{b}}$, referente ao ciclo de governo 2004-2007. De acordo com a pesquisadora, o governo autorizou os seguintes percentuais e montantes para a área "desporto e lazer" no referido ciclo: 40,45\% (R\$ 1.481.853.374,00) para o esporte de rendimento, 40,72\% (R\$1.491.901.094,00) para o esporte de participaçáo, 13,00\% (R \$ 476.371.928,00) para o esporte educacional, e 5,82\% ( $\$$ \$ 213.253.803,00) para outros programas e ações que não se encaixam em nenhuma destas dimensóes. Este planejamento, no entanto, não foi cumprido e os recursos foram alocados da seguinte forma: 66,32\% ( $\mathrm{R} \$ 847.435 .373,78)$ para o esporte de rendimento, 7,38\% (R \$94.311.053,67) para o esporte de participação, 12,69\% (R \$ 162.160.546,36) para o esporte educacional, e 13,61\% (R\$173.924.520,41) para outros programas e açóes que não se encaixam em nenhuma destas dimensóes. A maior parte das verbas destinadas ao esporte de rendimento - 88,16\% do total autorizado e $96,75 \%$ do total pago - foi para o Programa "Rumo ao Pan 2007".

Pelo que tudo indica, como o Brasil estará sediando em breve os Jogos Olímpicos e Paralímpicos Rio 2016, os investimentos continuarão privilegiando o esporte de rendimento. Isto pode ser observado, por exemplo, no Dossiê de Candidatura ${ }^{62}$ e no Caderno de Legados ${ }^{63}$, ambos documentos oficiais onde o governo brasileiro apresenta suas promessas de legado esportivo para o país decorrentes da realização dos 
Jogos Olímpicos e Paralímpicos Rio 2016. Ao mesmo tempo em que estes documentos prometem o desenvolvimento do esporte educacional e de participaçáo, o planejamento estrutural e financeiro para que isto aconteça se centra quase que exclusivamente no esporte de alto rendimento, principalmente no que tange ao desenvolvimento de infraestrutura esportiva voltada para este tipo de esporte e para a realização dos Jogos. Embora o governo brasileiro e os governos de diversos países que sediaram megaeventos esportivos aleguem que a construção de estruturas esportivas para a realização destes eventos favorece a população, isto não tem se concretizado na maioria dos casos. Um estudo de ALm ${ }^{1}$ bem exemplifica esta realidade. $\mathrm{O}$ autor analisou 75 instalaçóes esportivas construídas para sediar grandes eventos em 20 países. A conclusão foi a de que a maior parte destas instalações foi abandonada e/ou está sendo subutilizada, uma vez que foram planejadas para satisfazer os requerimentos e demandas dos promotores dos eventos e náo as demandas e necessidades da população local.

Não precisamos ir longe para verificarmos esta realidade tendo em vista o que aconteceu e vem acontecendo com as estruturas esportivas construídas e/ou reformadas para os Jogos Pan-americanos Rio 2007. Estas estruturas supostamente seriam um legado para a população e serviriam como estruturas para os Jogos Olímpicos e Paralímpicos no Rio de Janeiro, caso o país viesse a sediar estes Jogos. O parque aquático Maria Lenk, por exemplo, ficou subutilizado servindo como sede para apenas algumas raras competiçóes. Hoje está passando por uma reforma milionária para ser adaptado para as disputas de polo aquático durante os Jogos Rio 2016. O velódromo da Barra, considerado um dos melhores do mundo, também foi desmontado para a construção de outro que atendesse as exigências do COI para os Jogos Rio 2016. O estádio João Havelange, conhecido como "Engenhão", foi cedido para um clube de futebol privado, o Botafogo, e toda a estrutura desenvolvida no estádio para o atletismo está desperdiçada. O Complexo Esportivo do Maracanã, reformado para os Jogos Rio 2007, passou por reformas para a Copa do Mundo de Futebol em 2014 e precisará passar por novas reformas para os jogos Rio $2016^{64}$.

\section{Sem planejamento, não há desenvolvimento}

A construção de legados positivos para os países hospedeiros não brotam do acaso ${ }^{1-3,5-16}$. Todo o processo de planejamento e construçáo de legados é dirigido "pelas aspiraçóes e açóes de agentes bem posicionados cujas definiçóes de legado e desenvolvimento estão alinhadas com uma perspectiva neoliberal que reflete o seu posicionamento privilegiado em relações de poder nos níveis local, nacional e/ou global"23. Ou seja,

os principais beneficiários de legados de desenvolvimento planejado são aqueles cujas vozes são representadas durante o processo de preparaçáo para a candidatura, planejamento inicial, alocação de recursos, formulação de políticas públicas e implementaçấo de programas. Para aqueles que influenciam o fluxo de capital associado com o evento, os benefícios podem ser extensivos. Para populaçóes socialmente excluídas e para aqueles que não têm poder e acesso a recursos, os benefícios são raros embora sejam amplamente divulgados na narrativa promocional utilizada para se ganhar suporte popular para a candidatura do país para sediar o evento ${ }^{23}$.

A construção de legados precisa ser minuciosamente planejada ${ }^{6,13,29}$. Por exemplo, se a meta é promover a utilização das estruturas esportivas que serão construídas para a realizaçáo dos megaeventos, seja para a promoção do esporte de rendimento ou do esporte de participaçáo, faz-se necessário que durante o processo de planejamento para a construçáo das mesmas se atente para questôes tais como: Quem será o público alvo? Como estas estruturas podem ser construídas de forma a otimizar a sua utilização por este público? Como esta utilização será incentivada e viabilizada?

Se a meta é a promoção da prática de atividades físicas e esportivas para o lazer e saúde da população, as partes interessadas - o que inclui cidadãos comuns e possíveis usuários - devem realizar um planejamento conjunto considerando questóes tais como: quem será o público alvo, onde as atividades vão ocorrer, como os programas serão financiados e implementados, como as pessoas irão chegar até o local da prática, e como a participação das pessoas será integrada com o seu cotidiano. Sem este tipo planejamento os espaços e programas criados provavelmente ficarão subutilizados e/ou serão apropriados por pessoas ou grupos influentes para seu benefício próprio.

Se a meta é a promoção da educaçáo física e do esporte escolar, ou mesmo o acesso dos alunos à uma maior diversidade de práticas corporais e esportivas, 
necessita-se de estratégias concretas para que isto aconteça, como por exemplo, a capacitação de profissionais da educação física e a oferta de espaços e materiais.

Se a meta é a promoção de uma maior cultura esportiva e valores olímpicos (amizade, excelência e respeito) e paralímpicos (determinação, coragem, igualdade e inspiração) via currículo escolar, as escolas e seus professores precisam de recursos, suporte e benefícios para que possam se engajar nesta tarefa. No caso do Reino Unido, por exemplo, o governo disponibilizou um programa educacional chamado de "Get Set" destinado à escolas, universidades e autoridades educacionais vinculadas com os Jogos Londres 2012. Este programa oferece uma vasta biblioteca online com recursos interativos tais como artigos, filmes, jogos, entre outros materiais, para motivar a imersão em conteúdos e experiências relacionadas com o esporte, com os valores olímpicos e com os Jogos Olímpicos e Paralímpicos de Londres. A implementação deste programa, no entanto, ficou prejudicada, uma vez que faltou preparação e incentivos para os professores se engajarem em mais esta tarefa além de tudo o mais que precisam desenvolver no cotidiano da escola ${ }^{65}$. Algumas iniciativas de capacitação de professores e elaboração de materiais didáticos para a promoção de metas similares estão em andamento no Brasil. Estas iniciativas, no entanto, ainda são tímidas considerando-se o número de escolas, profissionais e alunos que fazem parte do sistema educacional do país.

Se a meta é a promoção de uma maior cultura esportiva através da mídia, conforme afirmou o Prof.Dr. Giovani Pires em entrevista concedida para outro projeto de pesquisa da mesma autoria, esta e seus profissionais precisam de qualificação para lidar com o esporte como um fenômeno histórico, social e cultural que vai muito além do que acontece nas quadras, piscinas, campos esportivos, etc. Ela precisa também se preparar para informar o público sobre as regras, normas, aspectos técnicos e táticos, códigos de ética, agentes e intencionalidades que interferem com o espetáculo esportivo ${ }^{\mathrm{c}}$.

Existe, no senso comum uma crença, denominada pelo sociólogo Jay Coakley como "the great sport myth" (o grande mito do esporte), onde se acredita que a atividade esportiva é essencialmente "pura" e "boa" ". Os adeptos deste mito acreditam que a atividade esportiva automaticamente promove saúde, bom caráter, socialização e cooperação entre os indivíduos. Estas pessoas tendem a não perceber que, dependendo de como ela é praticada, ela pode promover justamente o inverso de tudo isto. Ela pode, por exemplo, causar a lesôes irreversíveis devido a exageros no treinamento, bem como levar a trapaças e a utilização de substancias para que se possa atingir a vitória a qualquer custo. Para as pessoas que acreditam no "grande mito", é uma grande alegria o fato de se poder utilizar do esporte - percebido por elas como fonte de prazer e de desenvolvimento inúmeras qualidades - como uma plataforma para apresentar o seu país e a sua cultura para o resto do mundo. Esta crença de que o esporte automaticamente promove coisas boas para todos tende a prejudicar o envolvimento de seus adeptos em uma análise mais crítica sobre o esporte em si e sobre o fato de se hospedar - ou não - um megaevento esportivo. Isto afeta também o envolvimento das mesmas nos processos de planejamento e construção de legados a partir destes eventos ${ }^{23}$.

\section{Considerações finais}

Grandes organizaçóes esportivas, tais como a FIFA e o COI, controlam a realização dos megaeventos sob sua tutela. As suas metas e demandas, e aquelas dos agentes que normalmente participam dos processos de licitação, planejamento e avaliação destes eventos, tendem a se sobrepor à metas e demandas da maior parte da população dos países hospedeiros. $\mathrm{O}$ tipo de desenvolvimento proposto, planejado, financiado, priorizado, e implementado por estas instituiçóes e agentes é tendencioso. O suposto legado que é produzido, embora em grande parte construído com verbas públicas, tende a beneficiar de forma majoritária estas instituiçóes e agentes, bem como a seus aliados que possuem acesso a informaçóes privilegiadas e capital suficiente para desenvolver projetos que conseguem gerar lucro dentro do curto prazo estabelecido para a preparação e realização dos eventos.

Embora algumas vozes críticas venham a se opor à realização de megaeventos esportivos, a oposição do público em geral tende a ser prejudicada devido à falsas crenças, fundadas no senso comum, em relação aos supostos benefícios do esporte e da realização de megaeventos esportivos ${ }^{4}$. A população, a exemplo do que vem historicamente acontecendo em diferentes países, tende a acordar para as possíveis consequências negativas da realização destes eventos tarde demais: 
depois que todo o planejamento, metas de desenvolvimento, planos de legados, e dotação orçamentária estão estabelecidos. Consequentemente, as suas açóes tendem a se focar em protestos contra decisōes já tomadas, a exemplo do que aconteceu no Brasil durante as manifestaçôes de 2013. Ou seja, as pessoas em geral não se engajam efetivamente, em tempo hábil, no processo de planejamento e construçâo de legados positivos para o seu país/cidade.

Os megaeventos esportivos estão profundamente enraizados em nossa sociedade e vão continuar acontecendo, independentemente de protestos. Eles são atrativos, possuem um grande poder mobilizador, e embora apresentem problemas, possuem também potenciais que podem ser devidamente explorados em prol do bem comum. Para isto, no entanto, é necessário que a decisão para se sediar, ou não, estes eventos, esteja alinhada com as metas de desenvolvimento de longo prazo das cidades e países sede ${ }^{23}$. Esta decisão precisa também ser condizente com a realidade sociocultural destas cidades e países, bem como com a sua capacidade de fornecer a infraestrutura e recursos necessários para se hospedar o evento ${ }^{66}$. Atendidas estas condiçóes, e garantindo-se um grau de autonomia para se adaptar algumas normas instituídas pelos órgáos reguladores maiores tais como o $\mathrm{COI} e$ a FIFA, talvez existam mais chances de se produzir legados positivos para o desenvolvimento do país de uma forma geral, e do esporte, mais especificamente, de uma forma sustentável e de longo prazo. No caso do esporte, os megaeventos esportivos poderiam se constituir em oportunidade de se difundir uma cultura esportiva mais forte no país não somente no sentido de se promover os níveis de atividade física e esportiva da população e se aprimorar o nível de desempenho dos atletas de alto-rendimento, mas também de se fomentar o conhecimento e entendimento, por parte da população em geral, acerca das diferentes modalidades esportivas e complexidades envolvidas no fenômeno esportivo (fatores sociais, psicológicos, culturais, etc.).

A promoçáo de desenvolvimento a favor dos cidadáos e das cidades e países sede em decorrência da realização de megaeventos esportivos se constitui em um grande desafio. Este tipo de desenvolvimento não se dá magicamente e automaticamente como uma consequência direta deste tipo de eventos. As açôes em prol do mesmo precisam ser planejadas, executadas e avaliadas com a participação das partes interessadas, incluindo representantes da população que será diretamente afetada com a realização dos referidos eventos. Sáo necessárias pesquisas na área no sentido de se levantar exemplos de eventos bem sucedidos. A partir destes exemplos, talvez possamos delinear algumas estratégias que possam ajudar a alavancar a construção de legados positivos em países sede.

\section{Notas}

a. Esta pesquisa é desenvolvida através de entrevistas com uma amostra representativa de pessoas acima de 15 anos de idade, de diferentes idades, de cada país participante da União Europeia.

b. O Portal Siga Brasil é um portal de livre acesso disponível online que se constitui em um sistema de informaçóes orçamentárias gerais avançadas. Para maiores informaçóes verificar no seguinte endereço: http://wwwl2.senado.gov.br/ orcamento/sigabrasil.

c. Entrevista concedida por Pires, Giovani. Projeto de pesquisa “Possíveis legados esportivos no Brasil”. [ago. 2013]. Entrevistadora Doralice Lange de Souza. Brasília; 2013.

\section{Abstract}

Legacies of sport mega-events: considerations from a critical perspective

One of the main arguments for the realization of sport mega-events is that they generate economic, social, political and sport legacies for the hosting cities / countries. The goal of this paper is to discuss the notion of development on the agenda of these events, based on authors who have been discussing this issue. We verified that the type of development facilitated by these events has been primarily benefiting well positioned agents with privileged access to decision makers at the expense of a type of 
development that could favor the population in general. The promotion of development for the common good is possible only to the extent that the decision to host - or not host - sport mega-events is aligned with the long-term development goals of the cities and the host countries. This decision should also be consistent with the host's socio-cultural reality and its ability to provide the infrastructure and resources necessary to host the event. The realization of sport mega-events does not produce positive results automatically. For this to happen, it is necessary careful planning. For example, when considering the construction of sports venues and how they will be used after the event, people in charge should consider questions such as: Who will be responsible for maintaining them and which resources will be made available for this goal? Who will use these venues? What kind of support does the targeted pubic needs so that it can optimize their use? Both the process of legacy planning and the implementation and evaluation of actions to build this legacy should involve the participation of people who will be directly affected with the realization of the event.

KeY Words: Sport; Olympic Games; Paralympic Games; World Cup; FIFA; IOC

\section{Referências}

1. Alm J. World stadium index: stadiums built for major sporting events: bright future or future burden? Copenhagen: Play the Game and the Danish Institute for Sports Studies; 2012.

2. Cagan J, De Mause N. Field of schemes: how the great stadium swindle turns public money into private profit. Monroe: Common Courage Press; 1998.

3. Chalip L. Towards social leverage of sport events. J Sport Tourism. 2006;11:109-27.

4. Coakley J. Assessing the sociology of sport: on cultural sensibilities and the great sport myth. Int Rev Sociol Sport. In press; 2015.

5. Darnell S. Power, politics and sport for development and peace: investigating the utility of sport for international development. Sociol Sport J. 2010;27:54.

6. Darnell S. Sport for development and peace: a critical sociology. London: Bloomsbury Academic; 2012.

7. Donnelly P, Kidd B, MacNeill M, Harvey J, Houlihan B, Toohey, C. Opportunity knocks!: increasing sport participation in Canada as a result of success at the Vancouver Olympics. Toronto: Centre for Sport Policy Studies; 2008. [cited 2014 Nov. 18]. Available from: http://www.physical.utoronto.ca/Centre_for_Sport_Policy_Studies/Projects_and_Publications/Position_Papers.aspx.

8. Flyvbjerg B. Design by deception: the politics of megaproject approval. Harv Des Mag. 2005;50-9.

9. Hall CM. Urban entrepreneurship, corporate interests and sports mega-events: the thin policies of competitiveness within the hard outcomes of neoliberalism. In: Horne J, Manzenreiter W, editors. Sports mega-events: social scientific analyses of a global phenomenon. Oxford: Blackwell; 2006. p.59-70.

10. Horne J, Manzenreiter W. Accounting for mega-events: forecast and actual impacts of the 2002 Football World Cup Finals on the host countries Japan/Korea. Int Rev Sociol Sport. 2004;39:187-203.

11. Horne J, Manzenreiter W, editors. Sports mega-events: social scientific analyses of a global phenomenon. Oxford: Blackwell; 2006.

12. McCartney G, Thomas S, Thomson H, et al. The health and socioeconomic impacts of major multi-sport events: systematic review (1978-2008). Brit Med J. 2010;340:1229.

13. Minnaert L. An Olympic legacy for all? The non-infrastructural outcomes of the Olympic Games for socially excluded groups (Atlanta 1996-Beijing 2008). Tourism Manag. 2011;33:361-70.

14. New Zealand Tourism Research Institute. The benefits of events: an annotated bibliography. Auckland: AUT University; 2007.

15. Solberg HA, Preuss H. Major sporting events and long-term tourism impacts. J Sport Manag. 2006;21:213-34.

16. Spaaji R. Building social and cultural capital among young people in disadvantaged communities: lessons from a Brazilian sport-based intervention program. Sport Educ Soc. 2012;17:77-95.

17. Coalter F. Stuck in the blocks? A sustainable sporting legacy? In: Vigor A, Mean M, Tims C, organizers. After the Goldrush: a sustainable Olympics for London. London: IPPR and DEMOS; 2004. p.93-108. [cited 2014 Nov. 18]. Available from: http://www.demos.co.uk/files/AftertheGoldRush.pdf.

18. Coalter F. A wider social role for sport: who's keeping the score? London: Routledge; 2007. 
19. United Kingdom. Department for Culture, Media and Sport. Our promise for 2012: how the UK will benefit from the Olympic Games and Paralympic Games. London: Department for Culture, Media and Sport; 2007. [cited 2014 Nov. 18]. Available from: http://epress.lib.uts.edu.au/dspace/bitstream/handle/2100/449/Ourpromise2012.pdf?sequence=2.

20. United Kingdom. Department for Culture, Media and Sport. Creating a sporting habit for life: a new youth sport strategy. London: Department for Culture, Media and Sport; 2012. [cited 2014 Nov. 18]. Available from: http://www. culture.gov.uk/images/publications/creating_a_sporting_habit_for_life.pdf.

21. EdComs. London 2012 legacy research: final report. London: DCMS; 2007. [cited 2014 Nov. 18]. Available from: http://www.cwsportspartnership.org/files/london_2012_legacy_desk_research.pdf.

22. Hindson A, Gidlow B, Peebles C. The 'trickle-down' effect of toplevel sport: myth or reality? A case study of the Olympics. Aust Leis Recreation. 1994;4:16-24.

23. Coakley J, Souza DL. Sport mega-events: can legacies and development be equitable and sustainable? Motriz. 2013;19:580-9.

24. Bolsmann C. Representation in the first African World Cup: 'Worldclass', Pan-Africanism, and exclusion. Soccer Soc. 2012;13:156-72.

25. De Nooij M, Van Den Berg M, Koopmans C. Bread or games? A social cost-benefit analysis of the World Cup bid of the Netherlands and the winning Russian bid. J Sports Econ. 2011;14:521-45.

26. Hall CM. Sustainable mega-events: beyond the myth of balanced approaches to mega-event sustainability. 4o. Global Events Congress; 14 jul. 2010; Leeds, UK. Leeds: Universiry of Leeds; 2010. [cited 2014 Nov. 18]. Available from: http://www. academia.edu/822520/Sustainable_mega-events_beyond_the_myth_of_balanced_approaches_to_mega-event_sustainability.

27. Hall CM, Wilson S. Neoliberal urban entrepreneurial agendas, Dunedin Stadium and the Rugby World Cup: or 'If you don't have a stadium, you don't have a future'. In: Dredge D, Jenkings J, editors. Stories of practice: tourism policy and planning. Farnham: Ashgate; 2011. p.133-52.

28. Kay T. Accounting for legacy: monitoring and evaluation in sport in development relationships. Sport Soc. 2012;15:888-904.

29. Majumdar B, Metha N. Sellotape legacy: Delhi \& the Commonwealth Games. New Delhi: Harper Collins; 2010.

30. Whitson D, Horne J. Underestimated costs and overestimated benefits? Comparing the outcomes of sports mega-events in Canada and Japan. Sociol Rev. 2006;54:73-89.

31. Lenskyj H. Olympic industry resistance: challenging Olympic power and propaganda. Albany: State University of New York Press; 2008.

32. Gratton C, Simon S, Coleman R. The economic impact of major sport events: a review of 10 events in the UK. In: Horne J, Manzenreiter W, editors. Sports mega-events. Oxford: Blackwell; 2006. p.41-58.

33. Preuss H. The economics of staging the Olympics: a comparison of the Games 1972-2008. Cheltenham: Edward Elgar; 2004.

34. Jennings A. The new lords of the rings. London: Pocket Books; 1996.

35. Jennings A. Foul! The secret world of FIFA-bribes, vote rigging, and ticket scandals. New York: HarperSport; 2006.

36. Jennings A. Investigating corruption in corporate sport: the IOC and FIFA. Int Rev Sociol Sport. 2011;46:387-98.

37. Jennings A, Sambrook C. The great Olympic swindle: when the world wanted its games back. New York: Simon and Shuster; 2000.

38. Coakley J. Ideology doesn't just happen: sports and neoliberalism. Rev ALESDE. 2011:1:67-84.

39. Cornelissen S. Football's tsars: proprietorship, corporatism and politics in the 2010 FIFA World Cup. Soccer Soc. 2010;11:131-43.

40. ARUP. London Olympics 2012: costs and benefits summary. London: ARUP; 2002. [cited 2014 Nov. 18]. Available from: http://www.arup.com/_assets/_download/download368.pdf.

41. Torres S. Pan registrou caso de irregularidade e fiscalização frouxa. Folha de S.Paulo. 3 out. 2009. [citado ano mês dia]. Disponível em: http://www1.folha.uol.com.br/fsp/especial/ff0310200922.htm.

42. ESPN. Brasil olímpico: uma candidatura passada a limpo. [Programa de televisão exibido em 7 fev. 2009]. São Paulo: ESPN; 2009.

43. Gaffney C. Mega-events and socio-spatial dynamics in Rio de Janeiro, 1919-2016. J Latin Am Geogr. 2010;9:7-29.

44. Weed M, Coren E, Fiore J, et al. Developing a physical activity legacy from the London 2012 Olympic and Paralympic Games: a policy-led systematic review. Perspect Public Health. 2012;132:75-80.

45. Souza DL, Pappous S. Legados esportivos de megaeventos esportivos: uma revisão de literatura. Motrivivência. 2013;25:42-56.

46. London East Research Institute. A lasting legacy for London? Assessing the legacy of the Olympic Games and Paralympic Games. London: Greater London Authority; 2007.

47. Weed M. How will we know if the London 2012 Olympics and Paralympics benefit health? Brit Med J. 2010;340:1205-10. 
48. Veal AJ, Toohey K, Frawley S. The sport participation legacy of the Sydney 2000 Olympic Games and other international sporting events hosted in Australia. J Policy Res Tourism Leis Events. 2012;4:155-84.

49. Weed M, Coren E, Fiore J, et al. A systematic review of the evidence base for developing a physical activity and health legacy from the London 2012 Olympic and Paralympic Games. Canterbury: Centre For Sport, Physical Education \& Activity Research; 2009.

50. UK Sport. The inspirational effect of major sporting events. London: UK Sport; 2011.

51. Pappous A. Do the Olympic Games lead to a sustainable increase in grassroots sport participation? A secondary analysis of Athens 2004. In: Savery J, Gilbert K, editors. Sustainability and sport: sport and society. Champaign: Common Ground; 2011. p.81-9.

52. Australian Sports Commission. Impact of hosting the Sydney 2000 Olympic and Paralympic Games on participation and volunteering in sport and physical activity in Australia. Canberra: Australian Sports Commission; 2001.

53. Bauman A, Ford I, Armstrong T. Trends in population levels of reported physical activity in Australia, 1997, 1999 and 2000. Canberra: Australian Sports Commission; 2001. [cited 2014 Nov. 18]. Available from: http://www.physicalactivity.tas.gov.au/trends.pdf.

54. Sport England. Active People Survey. London: Sport England; 2014. [cited 2014 Nov. 18]. Available from: http:// www.sportengland.org/research/who-plays-sport/national-picture/.

55. United Kingdom. Local Government Association. Councils report big rise in sports participation post-Olympics. London: Local Government Association; 2013. [cited 2014 Nov. 18]. Available from: http://www.local.gov.uk/web/ guest/media-releases/-/journal_content/56/10180/3905304/NEWS.

56. Weed M. Sports mega-events and mass participation in sport. In: Grix J, editor. Leveraging legacies from sports-events: concepts and cases. Houndmills: Palgrave MacMillan; 2014. p.39-49.

57. Purdue DEJ, Howe PD. Empower, inspire, achieve: (dis)empowerment and the Paralympic Games. Disabil Soc. 2012;27:903-16.

58. Wolbring G, Litke B. Superhip to supercrip: the 'trickle-down' effect of the Paralympics. Boston: TheConversation. com; 2012. [cited 2014 Nov. 18]. Available from: https://theconversation.com/superhip-to-supercrip-the-trickle-down-effect-of-the-paralympics-9009.

59. British Broadcasting Corporation. UK Sport Rio 2016 funding defended by sports minister [Internet]. London: BBC; 2012. [cited 2014 Jul 15]. Available from: http://www.bbc.co.uk/sport/0/olympics/20830754.

60. Mascarenhas F. Megaeventos esportivos e educação física: alerta de tsunami. Movimento. 2010;18:39-67.

61. Mascarenhas F, Athayde P, Santos M, Miranda N. O bloco olímpico: estado, organização esportiva e mercado na configuração da agenda Rio 2016. Rev ALESDE. 2012;2:15-32.

62. Reis AC, Sousa-Mast FR, Gurgel LA. Rio 2016 and the sport participation legacies. Leis Stud. 2014;33:437-53.

63. Souza DL, Castro SBE, Almeida BS, et al. Propostas de legados esportivos em função dos Jogos “Rio 2016”. Rev Bras Ciênc Esporte. No prelo 2014.

64. Filipo L. O legado do Pan: prós, contras e uma longa caminha até o Rio 2016 [Internet]. Rio de Janeiro: Globo Esporte; 2013. [citado 10 mar. 2014]. Available from http://globoesporte.globo.com/olimpiadas/noticia/2013/05/o-legado-do-pan-pros-contras-e-uma-longa-caminhada-ate-o-rio-2016.html.

65. Coventry City Council. Get Set Education Programee [Internet]. Coventry: Coventry City Council; 2012. [cited 2014 Jul 16]. Available from: http://london2012.cswp.org.uk/get-involved?level=National\&title=get-set-education-programme.

66. Black D. Megas for strivers: the politics of second-order events. In: Grix J, editor. Leveraging legacies from sports mega-events: concepts and cases. Houndmills: Palgrave MacMillan; 2014. p.13-23.

\section{Agradecimentos}

Agradecemos à Fundação Araucária que contribuiu com parte do financiamento deste trabalho. 
Coakley J \& Souza DL.

ENDEREÇO

Doralice Lange de Souza

R. Sen. Salgado Filho, 1800 - casa 11 - Guabirotuba 81510-001 - Curitiba - PR - BRASIL e-mail: desouzdo@post.harvard.edu
Recebido para publicação: 16/ 12/ 2014

1a. revisão: 17/ 05/ 2015

2a. revisão: 30/ 06/ 2015

Aceito: 03/ 07/2015 